REVISTA DE DERECHO UNED, NÚM. 27, 2021

\title{
ANÁLISIS LEGISLATIVO Y JURISPRUDENCIAL DE LAS UNIONES EXTRAMATRIMONIALES EN ITALIA ¿UN EJEMPLO PARA EL ORDENAMIENTO JURÍDICO ESPAÑOL?
}

\section{LEGISLATIVE AND JURISPRUDENTIAL ANALYSIS OF EXTRA- MARRIAGE UNIONS IN ITALY. AN EXAMPLE FOR THE SPANISH LEGAL SYSTEM?}

\author{
Jesús Daniel Ayllón García
}

Doctor en Derecho. Universidad de CANTABria.

Sumario: 1. Introducción. 2. Breve referencia a la legislación española sobre parejas de hecho. 3. Comentario a la ley núm. 76 de 20 de mayo de uniones civiles entre personas del mismo sexo y de la disciplina de la convivencia. 3. A. Uniones civiles entre personas del mismo sexo. 3. B. Convivencia de hecho. 3.B.1. Concepto de convivencia de hecho. 3.B.2. Contrato de convivencia. 3.B.3. Otros derechos de los convivientes de hecho. 4. Comentario de la Ordinaza de la Corte di Cassazione núm. 9178, de 13 de mayo de 2018. 5. Conclusiones.

Resumen: El Ordenamiento Jurídico italiano ha elaborado la $\mathrm{Le}$ gge 20 maggio 2016, n. 76. Regolamentazione delle unioni civil tra persone dello stesso sesso e disciplina delle convivenze, reguladora de las uniones civiles entre personas del mismo sexo y la convivencia de hecho entre personas tanto del mismo como de distinto sexo, introduciendo el régimen jurídico de dos nuevos modelos de familia de una manera cuidadosa y exhaustiva. En relación con el Ordenamiento Jurídico Español, cabe advertir que dichas instituciones guardan similitud con el matrimonio igualitario y con la institución de las parejas de hecho, respectivamente. La normativa italiana puede ser un modelo a 
seguir por el legislador español a la hora de actualizar y sistematizar la normativa en materia de parejas de hecho.

Palabras clave: Uniones de hecho, uniones civiles, Italia, España, matrimonio igualitario.

Abstract: The Italian Legal System has drawn up the Legge 20 maggio 2016, n. 76. Regolamentazione delle unioni civil tra persone dello stesso sesso e disciplina delle convivenze, regulating civil unions between people of the same sex and de facto coexistence between people of both the same and different sex, introducing the legal regime of two new family models in a careful and exhaustive manner. In relation to the Spanish Legal System, we would like to point out that these institutions are similar to equal marriage and the institution of domestic partnerships, respectively. The Italian regulations can be a model for the Spanish legislator to follow when updating and systematizing the regulations on de facto couples.

Keywords: De facto unions, civil unions, Italy, Spain, equal marriage.

Recepción original: 26-11-2020

Aceptación original: 5-1-2021

\section{INTRODUCCIÓN}

El modelo tradicional de familia, esto es, el matrimonio como único cauce para formar una familia legítima, ha sido superado no solamente en España, sino también en la mayor parte de los Ordenamientos Jurídicos europeos. En Europa y, concretamente en España al amparo del artículo 39 de su Carta Magna, actualmente, son admitidos como modelos de familia constitucionalmente protegidos las familias matrimoniales; las familias reconstituidas o step families; las familias monoparentales; las familias homoparentales; y las uniones o parejas de hecho, entre otras.

En el presente trabajo, vamos a centrar nuestro análisis en la legislación y jurisprudencia italiana sobre uniones extramatrimoniales y lo vamos a hacer por dos motivos. En primer lugar, debido a la cercanía respecto de la tradición jurídica civilista que presentan el ordenamiento jurídico italiano y el español; y, en segundo lugar, porque, a excepción de la normativa sobre parejas de hecho de la Comuni- 
dad Autónoma de la Región de Murcia de agosto de 2018², la normativa italiana sobre uniones de hecho ha sido la más reciente dentro del ámbito de la Unión Europea, datando del mes de mayo de $2016^{2}$. Para ello, vamos a realizar, en primer lugar, un comentario de la Ley de 20 mayo de 2016 que regula las uniones civiles entre personas del mismo sexo y la disciplina de la convivencia de hecho ${ }^{3}$, destacando las cuestiones más relevantes sobre ambas instituciones, donde analizaremos el concepto tanto de unión civil como de convivencia de hecho que contiene esta norma. Posteriormente, haremos una referencia específica al contrato de convivencia por el que se regulan las cuestiones patrimoniales de las uniones de hecho y, finalmente, nos detendremos en analizar la Ordinaza di Cassazione núm. 9178 de $2018^{4}$, que incide directamente sobre qué ha de entenderse en Italia por convivencia de hecho. A medida que vayamos desarrollando los distintos aspectos objeto de análisis haremos alguna referencia a la heterogénea y numerosa regulación española en materia de parejas de hecho, intentando buscar diferencias y similitudes, con el objetivo final de determinar si la legislación italiana debiera tomarse como un importante eje sobre el que pivotase la, ya adelantamos, necesaria reforma de la normativa sobre pareja de hecho en España.

\section{BREVE REFERENCIA A LA LEGISLACIÓN ESPAÑOLA SOBRE PAREJAS DE HECHO.}

Previamente a analizar las relaciones extramatrimoniales en el Ordenamiento Jurídico italiano, conviene hacer una referencia a la

1 Ley 7/2018, de 3 de julio, de Parejas de Hecho de la Comunidad Autónoma de la Región de Murcia. BOE núm. 183, de 30 de julio de 2018. Referencia: BOEA-2018-10759.

2 Si bien es cierto que Reino Unido ha promulgado la Ley de 26 de marzo de 2019 (Civil Partnerships, Marriages and Deaths (Registration etc) Act 2019), no podemos olvidar que dicho Estado salió de la Unión Europea a consecuencia del Brexit. Además, la legislación inglesa en esta materia no es de nueva creación, sino que es una actualización de una normativa ya existente, concretamente de la Civil Partnership Act 2004 que únicamente permitía las parejas de hecho entre personas del mismo sexo hasta que una sentencia de la Corte Suprema inglesa, de 27 de junio de 2018, Steinfeld and Keidan Vs. Secretary of State for Internationaln Development, ([2018] UKSC 32 On appeal from: [2017] EWCA Civ 81) reconoció el derecho de los heterosexuales a ser pareja de hecho; hecho que supuso la promulgación de la citada legislación del año 2019.

3 LEGGE 20 maggio 2016, n. 76. Regolamentazione delle unioni civil tra persone dello stesso sesso e disciplina delle convivenze. Gazzetta Ufficiale núm. 118, de 21 de mayo de 2016.

4 Ordinanza della Corte di Cassazione núm. 9178, de 13 de mayo de 2018, Civile Ordine, Sezione 3, Anno 2018. 
situación jurídica de la institución de las parejas de hecho en España, puesto que, si pretendemos, al menos en un principio, tomar como referencia la legislación italiana para trasponerla (en parte) en España, será necesario, al menos, conocer la situación legal actual en nuestro sistema jurídico.

Al contrario de lo que sucede en Italia, en España no tenemos una regulación sistemática sobre la institución de las parejas de hecho, desde el momento en que no tenemos una norma de rango estatal que discipline la materia. Únicamente existen tres disposiciones estatales que contemplan un régimen legal para tres ámbitos concretos que son: la pensión de viudedad ${ }^{5}$, la subrogación mortis causa del arrendamiento de vivienda ${ }^{6}$ y la valoración de daños en los accidentes de circulación ${ }^{7}$. Si bien es cierto que existen otras normas estatales que hacen referencia a las uniones extramatrimoniales ${ }^{8}$, las mismas no establecen ningún régimen jurídico limitándose exclusivamente a mentarlas, pero sin ni si quiera proporcionar un concepto de pareja de hecho, por lo que quedará al arbitrio judicial qué ha de entenderse por pareja de hecho en cada caso concreto, lo que presenta un importante vacío legislativo en el ordenamiento jurídico que produce una situación de inseguridad jurídica para todas aquellas personas que decidan acudir a la institución de las parejas de hecho para conformar una familia.

Los verdaderos protagonistas en esta materia han sido los legisladores autonómicos, quienes han sido los encargados de pergeñar el régimen jurídico de este modelo de familia, si bien algunas de estas normas se han visto implicadas en juicios de inconstitucional con un resultado negativo que ha dejado parte de los cuerpos normativos autonómicos vacíos de contenido9. Las diecisiete Comunidades Autónomas y las dos Ciudades Autónomas han elaborado su

5 Artículo 221 del Real Decreto Legislativo 8/2015, de 30 de octubre, por el que se aprueba el texto refundido de la Ley General de la Seguridad Social.

6 Artículo 16 de la Ley 29/1994, de 24 de noviembre, de Arrendamientos Urbanos.

7 Artículo 36.2 de la Ley 35/2015, de 22 de septiembre, de reforma del sistema para la valoración de los daños y perjuicios causados a las personas en accidentes de circulación.

8 A modo meramente ejemplificativo, pueden consultarse los art. $101 \mathrm{CC}$, art. 87 ter LOPJ o art. $23 \mathrm{CP}$, entre otros.

9 Véase al respecto: Sentencia del Tribunal Constitucional (Pleno), núm. 81/2013, de 11 de abril (Aranzadi: RTC 2013/81); Sentencia del Tribunal Constitucional (Pleno) núm. 93/2013, de 23 de abril (Aranzadi: RTC 2013/93); y Sentencia del Tribunal Constitucional (Pleno) núm. 110/2016, de 9 de junio (Aranzadi: RTC 2016\110). 
propia normativa sobre uniones de hecho ${ }^{10}$. Todo lo expuesto, nos lleva a la desafortunada afirmación de que en España existen un total de veintidós conceptos de pareja de hecho diferentes: tres a nivel estatal, diecisiete a nivel autonómico y dos de las Ciudades Autónomas de Ceuta y Melilla; conceptos que, si bien comparten unas notas comunes, presentan diferencias que pueden llegar a producir discriminaciones en varios ámbitos del Derecho ${ }^{11}$ en función del territorio en el que la pareja se halle inscrita. Además, como adelantábamos, cuando una norma como el Código Civil o el Código Penal hacen referencia a este modelo familiar en alguno de sus preceptos, de nada nos sirve que dispongamos de veintidós conceptos, pues a ninguno de ellos podemos acudir para entender qué es una pareja de hecho a efectos de esta normativa.

Basta con estas breves notas para, de forma introductoria, vislumbrar la situación jurídica de este modelo familiar en el Ordenamiento Jurídico Español.

10 Ley Foral Navarra 6/2000, de 3 de julio, para la igualdad jurídica de las parejas estables; Ley 11/2001, de 19 de diciembre, de Uniones de Hecho en la Comunidad de Madrid; Ley 18/2001, de 19 de diciembre, de Parejas Estables de la Comunidad Autónoma de Illes Balears; Ley de Principado de Asturias 4/2002, de 23 de mayo, de Parejas Estables; Ley 5/2002, de 16 de diciembre de Parejas de Hecho de la Comunidad Autónoma de Andalucía; Ley 5/2003, de 6 de marzo, para la regulación de las Parejas de Hecho de la Comunidad Autónoma de Canarias; Ley 5/2003, de 20 de marzo, de Parejas de Hecho de la Comunidad Autónoma de Extremadura; Ley $2 / 2003$, de 7 de mayo, reguladora de las parejas de hecho de la Comunidad Autónoma de País Vasco; Ley 1/2005, de 16 de mayo, de Parejas de Hecho de la Comunidad Autónoma de Cantabria; Ley 2/2006, de 14 de junio, de derecho civil de Galicia; Ley 25/2010, de 29 de julio, del libro segundo del Código civil de Cataluña; Decreto Legislativo 1/2011, de 22 de marzo, del Gobierno de Aragón, por el que se aprueba, con el título de "Código del Derecho Foral de Aragón», el Texto Refundido de las Leyes civiles aragonesas; Ley 5/2012, de 15 de octubre, de la Generalitat, de Uniones de Hecho Formalizadas de la Comunitat Valenciana; Ley 7/2018, de 3 de julio, de Parejas de Hecho de la Comunidad Autónoma de la Región de Murcia; Decreto 124/2000, de 11 de julio, por el que se regula la creación y el régimen de funcionamiento del Registro de Parejas de Hecho de Castilla-La Mancha; Decreto 117/2002, de 24 de octubre, por el que se crea el Registro de Uniones de Hecho en Castilla y León; Decreto 30/2010, de 14 de mayo, por el que se crea el Registro de Parejas de Hecho de La Rioja; Reglamento del Registro Uniones de hecho de Ceuta, de 11 de septiembre de 1998; Reglamento Regulador del Registro de Parejas de Hecho de la Ciudad Autónoma de Melilla, de 28 de enero de 2008.

11 Una de las discriminaciones más importantes se produce en el ámbito de la adopción, donde si bien se permite que tanto los matrimonios entre personas del mismo como de distinto sexo adopten, así como las parejas de hecho heterosexuales, únicamente se permite la adopción por parejas de hecho homosexuales en cinco de las diecisiete Comunidades Autónomas que conforman España. AYLLÓN GARCÍA, J.D., "Discriminación normativa de las parejas de hecho: TRHA y adopción», en Revista de Derecho de Familia, núm. 73, Aranzadi, 2016, págs. 329-345. 


\section{COMENTARIO A LA LEY NÚM. 76 DE 20 DE MAYO DE UNIONES CIVILES ENTRE PERSONAS DEL MISMO SEXO Y DE LA DISCIPLINA DE LA CONVIVENCIA.}

Tras un largo debate parlamentario y social, el 20 de mayo de 2016 fue promulgada en Italia la Ley Cirinná o la Legge núm. 76 de Regolamentazione delle unioni civili tra persone dello stesso sesso e disciplina delle convivenze $e^{12}$, que introdujo por vez primera, en Italia, el reconocimiento legal de las parejas conformadas por personas del mismo sexo ${ }^{13}$. Se trata de una norma que supone una conquista importante de la libertad y, sin entrar en los méritos de las elecciones amistosas, sentimentales y éticas de los ciudadanos, que son y deben seguir siendo personales, tiene como objetivo incorporar al ordenamiento jurídico soluciones a los problemas sociales que se sienten como irreprimibles, como es la conformación de una pareja con independencia de su orientación sexual.

Esta Ley consta de 69 apartados y para su correcto análisis hemos considerado conveniente dividirla en dos partes. Por un lado, del apartado 1 al apartado 35, que se encargan de regular la institución de las uniones civiles entre personas del mismo sexo; y, por otro lado, del apartado 36 al 65 que se encarga de regular la institución de la convivencia de hecho, permitida tanto entre personas del mismo como de diferente sexo.

En consonancia con lo expuesto, lo primero que queremos destacar es que el apartado 1 establece que la Ley se encarga de regular las uniones civiles entre personas del mismo sexo y la institución de la convivencia como dos instituciones diferentes.

\section{A. Uniones civiles entre personas del mismo sexo}

El apartado 1 de la Ley 76/2016 establece que la unión civil entre personas del mismo sexo es una formación social amparada en los artículos 2 y 3 de la Constitución Italiana, que recogen los principios de libertad de formaciones sociales en las que el individuo desarrolla su personalidad, así como los principios de igualdad, dig-

12 LEGGE 20 maggio 2016, n. 76. Regolamentazione delle unioni civil tra persone dello stesso sesso e disciplina delle convivenze. Gazzetta Ufficiale núm. 118, de 21 de mayo de 2016.

13 CARBONE, C., "Unioni civili tra persone dello stesso sesso e disciplina delle convivenze", en Appendice di aggiornamento al formulario notarile commentato, Wolkers Kluwer, Italia, 2016. Disponible en: https://legacyshop.wki.it/documenti/carbone_appendice_aggiornamento.pdf (última consulta el 18/11/2020). 
nidad y no discriminación por sexo, raza o religión, entre otras cualidades de la persona.

Para constituir una unión civil, que necesariamente ha de estar compuesta por dos personas mayores de edad del mismo sexo, la Ley establece que las partes han de dar su consentimiento en presencia de dos testigos ante el registrador civil, quien llevará a cabo la inscripción de la unión en el Registro del Estado Civil (apartados 2 y $3)$. En ese momento, las partes podrán elegir si asumen un apellido común, así como si se debe colocar o posponer el de una de las partes respecto del apellido común elegido (apartado10).

Entendemos que la unión civil entre personas del mismo sexo es una institución idónea para el libre desarrollo de la personalidad de los miembros de la pareja para constituir una familia, pero, al mismo tiempo, creemos que es diferente de la institución matrimonial recogida en el artículo 29 de la Constitución Italiana ${ }^{14}$. Con esta regulación, el legislador italiano ha creado una nueva institución, independiente de la del matrimonio tal como se regula por el Código Civil italiano y, reservada, únicamente, para personas de distinto sexo. Incluso, parte de la doctrina, defiende que el legislador italiano, mediante esta Ley, podría haber extendido el matrimonio a parejas homosexuales sin incurrir en una violación del art. 29 de la Constitución Italiana ${ }^{15}$.

En lo que se refiere al régimen jurídico de las uniones civiles, en algunos aspectos, se hace referencia a la legislación matrimonial, mientras que, en otras cuestiones, entiende la doctrina que se dictan normas que difieren sustancialmente respecto de la institución del matrimonio ${ }^{16}$. Nosotros nos posicionamos por la primera corriente, esto es, que el legislador italiano ha regulado las uniones civiles entre personas del mismo sexo intentando que su regulación no difiera, nada más que en lo imprescindible, de la legislación matrimonial, si bien no hace una equiparación entre ambas instituciones. En este mismo sentido se manifestó la Corte Constitucional Italiana en dos ocasiones: la primera de ellas fue en la Sentencia núm.

14 Art. 29 Constitución Italiana: La República reconoce los derechos de la familia como sociedad natural basada en el matrimonio. El matrimonio se regirá sobre la base de la igualdad moral y jurídica de los cónyuges, con los límites establecidos por la Ley como garantía de la unidad familiar.

15 PRISCO, I., "Il pluralismo familiare in italia: unioni civili e convivenze", en Actualidad Jurídica Iberoamericana Núm. 11, agosto 2019, págs. 82-84.

16 PIZZUTI, P., "Uniones civiles y relación laboral en el ordenamiento italiano", en Temas laborales núm. 149, 2019. págs. 132-133.

(C) UNED. Revista de Derecho UNED, núm. 27, 2021 
138 de 2010 ${ }^{17}$; y posteriormente, corroborando dicha decisión, en la Sentencia núm. 170 de $2014^{18}$. Ambas sentencias defendían que las uniones homoafectivas merecen tutela, porque deben englobarse en las "formaciones sociales" establecidas en el art. 2 de la Constitución Italiana, es decir, en toda forma de comunidad, simple o compleja, que permita y favorezca el libre desarrollo de la persona en la vida de relación, en el contexto de una valorización del modelo pluralista, de modo que las personas del mismo sexo tienen el derecho fundamental de vivir libremente una condición de pareja, obteniendo -en los plazos y con las modalidades y límites que establece la ley-el reconocimiento jurídico con los correspondientes derechos y deberes ${ }^{19}$. Además, como puntualiza el Tribunal, la interpretación lógico-evolutiva del art. 29 de la Constitución italiana, justificada por la evolución de la sociedad y de sus costumbres, no puede extenderse hasta llegar incluso a incidir en el núcleo de la norma, modificándola de modo que deba incluirse en la misma fenómenos y cuestiones que no fueron en absoluto considerados cuando fue emanada. En función de dichas consideraciones, y acorde con los pronunciamientos de los jueces nacionales ${ }^{20}$ y europeos ${ }^{21}$, el legislador ordinario italiano decidió no extender el matrimonio a las personas del mismo sexo, creando un instituto paralelo equiparado, de hecho, al matrimonio, pero sin modificar el Código Civil. Es más, según el apartado 20 de la Ley 76/2016, la legislación matrimonial recogida en el Código Civil únicamente será aplicable a la unión civil si se hace referencia expresa en dicha Ley a través de la reproducción del contenido de los artículos individuales del Código Civil o si se hace referencia expresa a su articulado. Comprobaremos inmediatamente cómo la unión civil aparece construida acorde a la institución del matrimonio y su regulación se basa en la previsión de reglas que, salvo alguna disparidad, trascriben el contenido de las disposiciones del Código Civil italiano dedicadas al matrimonio ${ }^{22}$.

17 Sentenza della Corte Costituzionale núm. 138, de 15 de abril de 2010, Foro Italiano, 2010, c. 1367.

18 Sentenza della Corte Costituzionale núm. 170, de 11 de junio de 2014, Foro Italiano 10/2014, c. 2675.

19 Sentenza della Corte Costituzionale núm. 138, de 15 de abril de 2010, Foro Italiano, 2010, c. 1367.

20 Sentenza della Cassazione núm. 8097, de 21 de abril de 2015; Sentenza della Cassazione núm. 2400, de 9 de febrero de 2015; y Sentenza della Cassazione núm. 4184, de 15 de marzo de 2012.

21 STEDH, de 21 de julio de 2015, rec. n. ${ }^{\circ} 18766 / 11$ y 36030/11.

22 DELL'ANNA MISURALE, F., "Unioni civili tra diritto e pregiudizio. Prima lettura del nuovo testo di legge", en Giustiziacivile.com, núm. 6, 2016, págs. 10-15. Disponible en: https:/www.unisalento.it/documents/20152/681357/Le+unioni+civili 
Una vez que hemos dejado sentado que las uniones civiles entre personas del mismo sexo y el matrimonio son instituciones diferentes para el ordenamiento italiano (al igual que sucede en el español $\left.{ }^{23}\right)$, y que su regulación únicamente difiere en algunos puntos, vamos a analizar el régimen jurídico que la Ley 76/2016 establece para las uniones civiles.

En cuanto a los requisitos para su constitución, ya hemos apuntado que se requiere inscripción en el registro del estado civil, al igual que el matrimonio y también es necesaria la intervención de testigos. Ahora bien, una diferencia entre el matrimonio y las uniones civiles en cuanto a su constitución se refiere, es que en estas últimas no se requiere de una previa publicidad (lo que podría entenderse que es el correlativo al expediente previo matrimonial del ordenamiento jurídico español) mientras que el matrimonio así lo exige $^{24}$. La constitución de la unión civil entre personas del mismo sexo quedará certificada por un documento que demuestra la constitución de la unión. Dicha certificación ha de prever la indicación del régimen económico y de la residencia constante la convivencia (apartado 9). Una vez constituida la unión civil, las partes adquieren los mismos derechos y asumen los mismos deberes en condiciones de igualdad; de la unión civil deriva la obligación mutua de asistencia moral y económica, así como el deber de convivencia. Además, se prevé que los miembros de la pareja contribuyan a satisfacer las necesidades domésticas atendiendo, cada una de ellas, a su capacidad económica (apartado 11). En estos mismos términos se expresa el artículo 143 del Código Civil italiano a la hora de regular los derechos y deberes de los cónyuges. Sin embargo, es digno de destacar que, a diferencia de lo previsto para el matrimonio, no existe entre los miembros de la unión civil el deber de lealtad, lo que supone que, aquellos que se unen civilmente, pueden legítimamente ser infieles hacia su pareja, a menos que ello se reconduzca a través de la responsabilidad aquiliana ${ }^{25}$.

\footnotetext{
+tra+diritto+e+pregiudizio+\%281\%29.pdf/7b6cf4de-9ef4-5d15-b08a-d7436a97cdef? version=1.0\&download=true (última consulta el 07/05/2020).

${ }^{23}$ Así lo defiende la jurisprudencia del Tribunal Supremo. Vid. Sentencia del Tribunal Supremo Sala Primera, Núm. 611/2005, de 12 de septiembre (Aranzadi: RJ 2005/7148); Sentencia del Tribunal Supremo. Sala de lo Civil, núm. 431/2010, de 7 de julio (Aranzadi: RJ 2010/3904); Sentencia del Tribunal Supremo, Sala de lo Civil, de 10 de marzo de 1998 (Aranzadi RJ: 1998/1272); y Sentencia del Tribunal Supremo, Sala de lo Civil, de 16 de diciembre de 1996 (Aranzadi: RJ 1996/9020).

24 CARBONE, C., "Unioni civili tra persone dello stesso sesso e... op. cit.

25 CARBONE, C., "Unioni civili tra persone dello stesso sesso e... op. cit.
} 
En lo que se refiere a los impedimentos para constituir una unión civil que se regulan en el apartado 4 de la Ley, cabe destacar que guardan gran similitud con los impedimentos matrimoniales regulados en los arts. 85 a 88 del Código Civil italiano, y son: la existencia previa de un vínculo matrimonial o una unión civil no disueltos antes de unirse civilmente; la concurrencia de una deficiencia psíquica (que se puede traducir como la inexistencia de la capacidad de obrar plena del ordenamiento jurídico español); la existencia de las mismas relaciones de parentesco y afinidad indicadas para el matrimonio en el art. 87 del Código Civil italiano ${ }^{26}$; y la condena en sentencia judicial firme a una de las partes por asesinato consumado o en grado de tentativa contra aquellos que están casados o unidos civilmente con la otra parte. La existencia de cualquiera de las causas mencionadas determina, según el apartado 5 de la Ley, la nulidad de la unión civil, que puede ser alegada por cualquiera que pueda demostrar un interés legítimo (apartado 6). Más allá de las causas de nulidad indicadas anteriormente, la unión civil, según el apartado 7 de Ley y con un contenido similar a lo previsto para el matrimonio en el art. 122 del Código Civil italiano, puede ser impugnada por la parte que ha dado su consentimiento cuando haya existido violencia o intimidación en dicho acto, o cuando haya habido un error en la identidad o las cualidades personales de la otra parte cuando se trate de la existencia de una enfermedad física o mental, que pueda influir en el desarrollo de la vida en común de la pareja.

El apartado 12 de la Ley 76/2016 reproduce el art. 144 CC italiano estableciendo que los miembros de la unión civil decidirán de mutuo acuerdo la vivienda que adquirirá la connotación de residencia familiar.

Por su parte, el apartado 13 parafrasea el art. 159 CC italiano, siguiendo casi por completo el modelo matrimonial de los regímenes económicos, estableciendo que el régimen económico constante la unión civil entre personas del mismo sexo, en ausencia de un acuerdo entre las partes, será el de la comunidad de bienes. En este apartado se reproduce también el contenido del art. 160 CC italiano especificando que las partes no podrán derogar ni los derechos ni los deberes previstos por la ley como resultado de la unión civil. Luego alude expresamente a las normas a las que se refieren los artículos $162,163,164$ y 166 CC italiano con respecto a la forma y modificación de los acuerdos de matrimonio, la simulación y la capa-

26 VENUTI, M.C., "La regolamentazione delle unioni civili tra persona dello stesso sesso e delle convivenze in Italia", en Política del diritto, núm. 47, 2016, págs. 100-101. 
cidad para su estipulación. El párrafo termina con una referencia a las secciones II, III, IV, V y VI del Capítulo VI del Código Civil sobre el régimen patrimonial familiar, que serán también aplicables a las uniones civiles ${ }^{27}$. Estas secciones se refieren la disciplina del fondo patrimonial, la comunidad de bienes legal, la comunidad convencional, a la separación de activos o régimen de separación de bienes y a la regulación de la empresa familiar.

El apartado 14 establece que, al igual que para el matrimonio, será de aplicación el artículo 342 ter del Código Civil, en aquellos supuestos en los que uno de los miembros de la unión civil atente contra la integridad física o moral o contra la libertad de la otra parte. De este modo, el juez, a instancia de parte, podrá obligar al que haya cometido la conducta perjudicial que abandone el hogar familiar y no se acerque a la víctima.

El párrafo 15 equipara a los cónyuges con las uniones civiles en relación con el nombramiento del administrador de apoyo (lo que sería el tutor o curador en el ordenamiento jurídico español), con la legitimación para instar el juicio de incapacidad, así como para instar la revocación de las medidas relativas cuando cese la causa de incapacidad.

El párrafo 16 permite la anulación del contrato de unión civil en el caso de se ejerza violencia a una de las partes de la unión civil por la otra al equiparar, también para dichos fines, al cónyuge en la disciplina dictada por el art. 1436 CC italiano. Además, también puede anularse el contrato si la violencia se dirige contra la persona o la propiedad de alguno de los descendientes o ascendientes de los miembros de la pareja.

El apartado 17 se refiere expresamente a los arts. 2118 y 2120 CC italiano, que establecen que la indemnización laboral por causa de muerte del empleado corresponderá al miembro supérstite de la unión civil, tal y como se prevé para el matrimonio ${ }^{28}$.

El párrafo 19 establece la aplicación a la unión civil de diferentes normas que son de aplicación a los matrimonios: la regulación de la pensión alimenticia prevista para los cónyuges contenida en el Título XIII del Libro I; la disposición del primer párrafo del art. 116 CC italiano sobre el matrimonio del extranjero que obliga a los futuros contrayentes a presentar una certificación que demuestre que no 85-87.

27 PRISCO, I., "Il pluralismo familiare in italia: unioni civili e... op. cit, págs.

28 PIZZUTI, P., “Uniones civiles y relación laboral en el ordenamiento... op. cit. págs. 137-139. 
están casados ni forman unión civil con otra persona en su país de origen; la disposición del art. 146 CC italiano sobre el abandono de la vivienda familiar; y la norma sobre la constitución del fondo patrimonial del art. 2647; finalmente también se aplica a las uniones civiles el art. 2653, primer párrafo, núm. 4 CC italiano para permitir la transcripción de las solicitudes de disolución de la unión.

Anteriormente hemos comentado que la normativa del Código Civil sólo se aplica a las uniones de hecho cuando así se prevea expresamente, sin embargo, el apartado 20 de la Ley 76/2016, establece que, en las demás leyes y reglamentos, la presencia de los términos "matrimonio", "cónyuge" y "cónyuges", es suficiente para llevar a cabo una equiparación normativa entre unión civil y matrimonio ${ }^{29}$. En resumen, este apartado 20, nos dice que todas aquellas referencias a la institución matrimonial se aplicarán a las uniones civiles entre personas del mismo sexo, a excepción de las normas contenidas en el Código Civil, que solo serán aplicables a esta institución si así se prevé expresamente. Además, este apartado hace referencia a las adopciones cuando excluye expresamente la aplicación directa de la ley de adopciones, pero especifica que «lo que está previsto y permitido en materia de adopción sigue vigente». Sin embargo, hemos de indicar que la legislación italiana "que sigue vigente" no prevé que las uniones civiles entre personas del mismo sexo puedan adop$\operatorname{tar}^{30}$. En un principio estaba previsto que la pareja homosexual pudiese adoptar al hijo de su pareja, sin embargo, dicha disposición tuvo que ser eliminada para poder proceder a la aprobación del texto definitivo tal y como se conoce hoy. No obstante, parte de la doctrina entiende que con una interpretación amplia del artículo 44 de la Ley sobre adopciones de Italia, atendiendo al interés superior

29 FERRANDO, G., "Le unioni civili: la situazione in Italia", en Giurisprudenza Italiana, 2016, págs. 1771-1779.

30 Para ser idóneo para adoptar, los solicitantes tienen que ser mayores de edad lo que, según la normativa italiana, significa haber cumplido los 18 años de edad. Pueden adoptar tan sólo solicitantes que llevan casados, tanto por lo religioso como por lo civil, al menos, 3 años. También es posible adoptar cuando no se da este último requisito, pero en tal caso los cónyuges deben demostrar que han tenido una relación de pareja de hecho durante el tiempo correspondiente. Respecto a las familias monoparentales pueden adoptar sólo en casos excepcionales, recogidos detalladamente en la legislación italiana: a) un menor es susceptible de adopción por un familiar suyo hasta sexto grado de consanguinidad o por una persona que ha tenido una relación muy cercana con el niño antes del fallecimiento de sus padres biológicos; b) cuando uno de los cónyuges quiere adoptar el menor adoptado por el otro cónyuge, y c) en los casos cuando el menor no puede ser alojado durante el período preadoptivo (acogida preadoptiva en familia). Además, la diferencia de edad mínima entre los adoptantes y el adoptado tiene que ser 18 años, y la máxima 45 años, siendo este requisito aplicable al más joven de los solicitantes. 
del menor, un miembro de la unión civil podrá solicitar la adopción del hijo biológico de su pareja ${ }^{31}$, lo que se conoce como la institución de stepchild adoption ${ }^{32}$. Es más, ya existe una línea jurisprudencial que comienza a aceptar este tipo de solicitudes ${ }^{33}$; línea jurisprudencial que va en sintonía con la dirección que sigue el Tribunal Europeo de Derechos Humanos ${ }^{34}$.

Por su parte, el apartado 21 se encarga de regular los derechos sucesorios de las uniones civiles indicando, de manera expresa, que serán de aplicación las normas previstas para el matrimonio en lo relativo a las causas de indignidad para suceder, a la sucesión intestada, a las normas que regulan la sucesión testamentaria y las legítimas, la colación y los pactos sucesorios ${ }^{35}$.

En los apartados 21 a 25 se regulan las causas de extinción de las uniones civiles. Fundamentalmente son dos: por muerte o declaración de fallecimiento de cualquiera de los miembros de la pareja de hecho (apartado 22); y cuando cualquiera de ellos, en solitario o conjuntamente, manifiesten ante el encargado del Registro del Estado Civil la intención de disolver la unión, para lo que habrá que esperar tres meses desde la formalización de la unión (tal y como sucede en España, por ejemplo, a la hora de solicitar la disolución del matrimonio, salvo tasadas causas) y para lo que no se requerirá una separación previa como se requiere para la disolución del matrimonio (apartado 23 a 25). 90-92.

31 PRISCO, I., "Il pluralismo familiare in italia: unioni civili e... op. cit, págs.

32 BLANCA, M., "Il comma 20 quale crocevia per l'inserimento della nuova disciplina delle unioni civile nel sistema", en Le unioni civili e le convivenze. Commento a la legge n. 76/2016 e ai d.lgs. n. 5/2017; d.lgs. n. 6/2017; d.lgs. n. 7/2017, MASSIMO BIANCA, C. (cura), G. Giappichelli Editore, 2017, págs. 271-273.

33 Sentenza della Corte di Cassazione, de 22 giugno 2016, n. 12962, Foro it., 2016, I, c. 2342. cfr., in motivazione, della Sentenza della Corte di Cassazione, de 30 settembre 2016, núm. 19599, Foro it., 2016, 11, I, c. 3329. Sugli effetti dell'adozione ex art. 44, lett d, l.ad. sul rapporto del minore con il genitore biologico: Trib. min. Palermo, 30 luglio 2017, www.articolo29.it (última consulta el 08/05/2020).

34 Sentencia del Tribunal Europeo de Derechos Humanos, CEDH, Grande Chambre, X y otros c. Austria , decisión de 19 de febrero de 2013. En dicha sentencia se establece que constituye una violación del art. 14, en conjunción con el art. 8, la disposición sobre la adopción de menores de una norma que regula de manera diferente las condiciones de ejercicio de la patria potestad para las parejas de facto del mismo sexo y para las de diferente sexo (HUDOC: http://hudoc.echr.coe.int/ fre? $\mathrm{i}=001-139676)$.

35 http://www.coupleseurope.eu/es/italy/topics/8-Qu\%C3\%A9-estipula-la-leycon-respecto-a-la-propiedad-de-parejas-de-hecho-registradas-y-no-registradas/ (última consulta el 05/05/2020). 
Los apartados 26 y 27 se encargan de determinar qué sucede con los efectos que tiene la rectificación del sexo en el registro civil. El primero de ellos determina que si en una unión civil entre personas del mismo sexo, una de ellas rectifica el sexo y ello supone que ahora la unión civil está compuesta por personas de distintos sexos, la unión civil se extingue, puesto que ya vimos que es una institución reservada exclusivamente para parejas homosexuales. Por su parte, el apartado 27 establece que si la rectificación del sexo se produce por parte de un cónyuge y el matrimonio no ha manifestado la voluntad de disolverse y de acabar con los efectos civiles del mismo, la pareja se transforma automáticamente en una unión civil entre personas del mismo sexo ${ }^{36}$. Si bien observamos que en este supuesto hay una conversión automática del matrimonio a las uniones civiles, no se prevé lo mismo para el caso contrario. Sin embargo, puesto que se ha producido una rectificación del sexo y ahora la pareja que antes constituía una unión civil, es una pareja de distinto sexo, nada les impide, a nuestro parecer, contraer matrimonio siguiendo las formalidades previstas en el Código Civil.

El resto de apartados relativos a las uniones civiles, esto es, del 28 al 34 se encargan de habilitar al Gobierno para que desarrolle la Ley que venimos comentando y de introducir algunas reformas en el Código Civil para ajustar la normativa a la realidad de este modelo familiar.

Finalmente, el apartado 35 se encarga de establecer que las disiposiciones comentadas tendrán plena eficacia desde la entrada en vigor de la Ley, esto es, desde el 5 de junio de 2016.

Llegados a este punto, podemos definir las uniones civiles italianas como aquellas entre personas del mismo sexo, en las que no concurren impedimentos legales, con plena capacidad de obrar, libres de Estado Civil (relación monógama) y, no vinculados por relación de parentesco, afinidad ni adopción.

Una vez analizada la primera parte de la Ley Cirinná, llegamos a la conclusión de que las uniones civiles entre personas del mismo sexo en Italia presentan una equiparación casi plena, excepto en la nomenclatura, con el matrimonio entre personas del mismo sexo regulado en España desde el año 2005 y, no se identifican demasiado con la institución de las parejas de hecho. Y ello lo decimos porque tanto el matrimonio igualitario en España como las uniones civiles entre personas del mismo sexo en Italia precisan de una inscripción

36 Esta regulación trae causa del pronunciamiento de la Sentenza della Corte Costituzionale. núm. 170 de 2014 (Gazzetta Ufficiale, 18/06/2014, núm. 26). 
en el registro civil, así como otras muchas formalidades que nada tienen que ver con los nimios requisitos formales exigidos a las parejas de hecho. Además, es indiscutible la semejanza de esta institución con el matrimonio entre personas del mismo sexo en España, desde el momento que hemos advertido que el legislador italiano ha intentado asemejar en todo lo posible dicha institución a la matrimonial ${ }^{37}$.

La mayor diferencia que podemos destacar entre el matrimonio igualitario en España y las uniones civiles entre personas del mismo sexo en Italia es que las primeras pueden adoptar y las segundas, tal y como hemos expuesto, lo tienen vetado, siendo su única posibilidad acudir a la adopción del hijo biológico de su pareja.

Ahora vamos a analizar la segunda parte de esta Ley, que se encarga de regular la institución de la convivencia de hecho, la cual, ya adelantamos, presenta mayores similitudes con la institución de las parejas de hecho de nuestro ordenamiento jurídico.

\section{B. Convivencia de hecho}

Previamente a la entrada en vigor de la Ley Cirinnà, no existía en Italia una regulación que disciplinase de modo unitario las relaciones de las parejas de hecho. Hubo varias proposiciones de ley, entre las que cabe destacar el llamado "Proyecto Cappiello" de 198838, que consideraba como parejas de hecho a las que habían convivido, al menos, tres años y que, o bien se hallaban inscritas en un registro especial, o bien habían manifestado su condición en documento público; no obstante, si la pareja había tenido descendencia se aplicaba la regulación con independencia de la duración de la convivencia. Este proyecto no salió adelante porque se entendía, entre otras cuestiones y al igual que ha sucedido en España con la Ley navarra ${ }^{39}$, que se vulneraba el libre desarrollo de la personalidad, al imponerse a los convivientes de hecho un régimen de convivencia por el mero hecho de tener descendencia común, sin ningún otro requisito ${ }^{40}$.

37 MASSIMO BIANCA, C., "L'introduzione dell' unione civile” en Le unioni civili e le convivenze. Commento a la legge n. 76/2016 e ai d.lgs. n. 5/2017; d.lgs. $n$. 6/2017; d.lgs. n. 7/2017, MASSIMO BIANCA, C. (cura), G. Giappichelli Editore, 2017, págs. 1-2.

38 ANGELI, F., Coppia e famiglia tra desiderio di mutamento e ricerca di stabilità, Unione italiana consultori prematrimoniali e matrimoniali, 1998, pág. 43.

39 Ley Foral 6/2000, de 3 de julio, para la igualdad jurídica de las parejas estables. BOE núm. 214, de 06/09/2000.

40 Vid. Sentencia del Tribunal Constitucional (Pleno) núm. 93/2013, de 23 de abril (Aranzadi: RTC 2013/93). 
No obstante, el hecho de que antes de la Ley Cirinnà no existiese una regulación unitaria de las parejas hecho, no suponía que la convivencia de hecho fuese un fenómeno jurídicamente ignorado, sino que, al igual que sucede en España, el legislador estatal italiano, a través de normas dispersas regulaba algunas situaciones concretas que consideró merecedoras de protección jurídica. En Derecho social se preveían prestaciones económicas y sanitarias que equiparaban las parejas de hecho a las matrimoniales (jubilación de funcionarios militares y civiles, prestaciones en supuestos de desgracias...) y, a finales de los años 70, la Ley n. 194/1978, se introdujo la figura del conviviente en lo que a la interrupción voluntaria del embarazo se refiere. Por otra parte, en el Derecho fiscal, al igual que sucede en España como norma general, ignora a los convivientes de hecho y los hace tributar como extraños ${ }^{41}$. También, al igual que sucede en el ordenamiento penal español, el conviviente es equiparado al cónyuge en determinados supuestos, como en el supuesto de la no obligación de declarar contra su pareja ${ }^{42}$. Otra semejanza con el ordenamiento español, la encontramos en relación con la negativa a reconocer derechos intestados a los convivientes supérstites ${ }^{43}$ y el reconocimiento de la subrogación mortis causa del arrendamiento de vivienda ${ }^{44}$. En Italia fue el Tribunal de Casación ${ }^{45}$ el que consideró que entre los sucesores en el contrato de arrendamiento por muerte había que incluir al conviviente de hecho y así se hizo en la Ley 392/1978 con la expresión "afines que habitualmente conviven con él (arrendatario fallecido)". Por el contrario, en Italia la jurisprudencia venía negando el derecho de indemnizaciones por muerte del conviviente al miembro de la pareja supérstite ${ }^{46}$, al contrario de lo que sucedía en nuestro ordenamiento jurídico.

Como puede observarse, antes de la entrada en vigor de la Ley Cirinnà, no existían grandes diferencias entre el ordenamiento jurídico español y el italiano en lo que al Derecho estatal se refiere.

41 Artículo 82 de la Ley 35/2006, del Impuesto sobre la Renta de las Personas Físicas.

42 Artículo 416 Ley de Enjuiciamiento Criminal.

43 Vid. AYLLÓN GARCÍA, J.D., "Presente y futuro del derecho sucesorio de las parejas de hecho", en DE SALES CAPILLA RONCERO, F.; ESPEJO LERDO DE TEJADA, M.; y ARANGUREN URRIZA, F.J. (Dir.), Las legitimas y la libertad de testar: Perfiles críticos y comparados, Aranzadi, 2019. pp. 257-285.

44 Artículo 16 Ley de Arrendamientos Urbanos.

45 Sentenza della Corte Constituzionale, 7 abril 1988, núm. 404, Foro it. 1988, I, c. 2515 .

46 MARTÍN CASALS, M., "Informe de Derecho comparado sobre la regulación de la pareja de hecho", en Anuario de Derecho Civil, Fascículo 4, 1995, págs. 17311738. 
Expuesta cual era la situación anterior a la entrada en vigor de la Ley de 20 de mayo que regula la disciplina de la convivencia, vamos ahora a analizar la actual regulación de las uniones convivenciales de hecho que se encuentra recogida, tal y como hemos apuntado con anterioridad, en los apartados 36 a 65 de la Ley que venimos estudiando. Se puede decir que la Ley Cirinnà regula la disciplina de la convivencia en dos niveles: uno, que denominaremos "básico" y que se refiere a todas las parejas que se califican como cohabitantes de hecho de conformidad a la definición del apartado 36; y otro destinado a una protección más específica, destinado a aquellos cohabitantes de hecho que han celebrado el llamado contrato de convivencia, disciplinado en los apartados 50 a 64.

\section{B.1. Concepto de convivencia de hecho}

Actualmente, en la legislación italiana, la convivencia de hecho viene definida en el apartado 36 de la Ley Cirinnà como la situación de dos personas mayores de edad ${ }^{47}$, unidas de manera estable por lazos afectivos de pareja, que se asisten moral y materialmente de manera recíproca y que no están vinculados por lazos de parentesco adoptivos ni de afinidad, ni por matrimonio, ni mediante una unión civil. De este modo, al no hacer la norma alusión al género de los miembros de la pareja, se entiende que esta institución incluye tanto a las parejas heterosexuales como a las homosexuales ${ }^{48}$. En otras palabras, la disciplina de la convivencia está destinada a aquellos que no han formalizado su relación afectiva de pareja, ya sea con la celebración del matrimonio (si los miembros de la pareja son de distinto sexo), o con la conformación de la unión civil (en el caso de personas del mismo sexo).

Además de los requisitos personales que establece el apartado 36 , debemos tener en cuenta la importancia que tiene el requisito

47 La falta de referencia normativa a la disciplina del matrimonio en materia de mayoría de edad para los convivientes de hecho debe llevar a creer que la hipótesis de que la cualidad de la convivencia de hecho pueda reconocerse incluso al menor de edad está excluida, ya que, de lo contrario, el sistema permitiría, como se permite en el matrimonio, a los menores de 16 años que hayan obtenido la autorización para contraer matrimonio una vez que el juez haya verificado su madurez psicofísica, conformar una pareja de hecho. Por tanto, en la convivencia de hecho en Italia, no se permite que los miembros de la pareja sean menores de edad, o lo que es lo mismo, no existe dispensa de edad para constituirse como conviviente de hecho y es requisito sine qua non tener, al menos, 18 años.

48 VENUTI, M. C., "La regolamentazione delle unioni civil tra persone dello... op. cit. págs. 114-120. 
de la "convivencia" para este tipo de uniones; requisito que se desprende de una interpretación sistemática de los apartados 36 y 37 . Así, el apartado 37 hace referencia a la necesidad de que los miembros de la pareja manifiesten mediante una declaración personal la intención de constituir una convivencia con su correspondiente inscripción en el registro de población de residentes ${ }^{49}$. De ello, parece desprenderse que, en un principio, la convivencia es un requisito indispensable para entender que nos encontramos ante una convivencia de hecho, sin embargo, y tal como analizaremos con mayor detenimiento más adelante, tras una resolución de la Corte de Casación $^{50}$, si bien la convivencia es un requisito a tener en cuenta, no es un requisito sine qua non para reconocer la existencia de una convivencia de hecho como institución familiar.

Los apartados 38 a 41 se encargan de equiparar a los convivientes de hecho con los cónyuges en todo lo relativo a la legislación penitenciaria y en lo referente a los derechos en caso de hospitalización o enfermedad de su pareja, respectivamente, otorgando al conviviente la posibilidad de ostentar un poder de representación en cuestiones relativas a las decisiones de salud en caso de presentar una incapacidad para comprender y tomar decisiones así como en caso de muerte para cuestiones tales como la donación de órganos, métodos de tratamiento corporal y lo relativo a la celebración del sepelio.

Por su parte, los apartados 42 y 43 se encargan de regular el uso de la vivienda habitual por el conviviente supérstite en el supuesto de que la vivienda perteneciese, en exclusiva, al conviviente difunto. De este modo, se establece que el conviviente supérstite podrá habitar esa vivienda o bien por un periodo de 2 años, o bien por un periodo igual al tiempo de convivencia si es superior a dos, sin superar nunca los 5 años. No obstante, hay que tener en cuenta que en caso de que los hijos comunes de la pareja sean menores de edad o tengan la capacidad modificada judicialmente y convivan con el supérstite, éste podrá continuar viviendo en la residencia común por un periodo nunca inferior a tres años. Este derecho podría asimilarse a lo que en el ordenamiento jurídico español denominamos un legado a favor de una persona, en este caso, a favor del conviviente supérstite. Este derecho a convivir en la residencia común propiedad

49 El artículo 4 del Decreto del Presidente della Repubblica, 30 maggio 1989, núm. 223 que aprueba el reglamento de registro de la población residente establece que, a efectos del registro, se entiende por familia al grupo de personas vinculadas por matrimonio, parentesco, afinidad, adopción, tutela o por vínculos afectivos que cohabiten y residan en el mismo municipio.

50 Ordinanza de Cassazione núm. 9178, del 13 maggio 2018, Civile Ordine, Sezione 3, Anno 2018. 
del difunto se extingue en caso de que el miembro supérstite contraiga matrimonio, unión civil, nueva pareja de hecho o deje de vivir de manera estable en la vivienda ${ }^{51}$. Pese a que la norma no dice nada al respecto, se entiende que el derecho a residir en esa vivienda subsistirá en estas situaciones, siempre y cuando existan hijos del difunto, en cuyo caso, el derecho lo tendrán sus descendientes y no el cónyuge, todo ello, atendiendo al interés superior del menor ${ }^{52}$. En el ordenamiento jurídico español encontramos una importante laguna normativa al respecto, pues el régimen de uso y atribución de la vivienda familiar está recogido en el artículo $96 \mathrm{CC}$, donde no se hace referencia alguna a las uniones de hecho y, por tanto, es aplicable únicamente en caso de crisis matrimonial.

El apartado 44 se encarga de regular la subrogación mortis causa del arrendamiento de vivienda familiar, coincidiendo en este punto con la legislación española como ya tuvimos ocasión de apuntar. Sin embargo, en este supuesto no se exigen unos requisitos más severos para los convivientes de hecho que para el matrimonio, como sucede en España ${ }^{53}$, sino que es suficiente con ser pareja de hecho conforme a la descripción del apartado 36 de la ley, por lo que, entendemos, que el legislador italiano no incurre en la discriminación en la que incurre el español, ya que utiliza un único concepto de convivencia de hecho, sin plazos, para todo el territorio italiano y no acude a normas especiales con distintos plazos de convivencia como vimos que hacía el legislador español.

El apartado 45 de la Ley hace una plena equiparación entre los cónyuges y los convivientes de hecho en materia de vivienda pública. Este precepto establece que en el caso de que pertenecer a una unidad familiar suponga una preferencia a la hora de asignar una vivienda pública (entendemos que se refiere a lo que en España se

51 Pese a que el ordenamiento jurídico español no contemple una norma similar. La jurisprudencia también ha establecido que el uso de la vivienda familia se extingue en el supuesto en el que el beneficiario de la vivienda familiar comience una nueva relación con otra persona. Vid. Sentencia del Tribunal Supremo, núm. 643/2018, de 20 de noviembre.

52 CIPPITANI, R. y COLCELLI, V., "La función innovadora del interés del menor en la jurisprudencia italiana", en El interés superior del niño en la jurisprudencia internacional, comparada y española, SANZ CABALLERO, S. (Dir.), Aranzadi, Thomson Reuters, 2017, págs. 207-209.

53 En España se exige un plazo de convivencia de, al menos, dos años, a no ser que hubiese descendencia común, en cuyo caso no será necesario que transcurran los dos años. Como podemos observar, el ordenamiento italiano no establece ningún plazo de convivencia, sino que basta con que sean pareja de hecho según el apartado 36 de la Ley para disfrutar del derecho a subrogarse en el arrendamiento en caso de muerte del otro conviviente. 
conoce como Viviendas de Protección Oficial), se entenderá que la convivencia de hecho formalizada según la Ley Cirinnà, se considera núcleo familiar y se equipara en el matrimonio a todos los efectos. Lo que parece una mera equiparación de derechos, consideramos que tiene un trasfondo mucho más importante, pues mediante esta disposición normativa se está introduciendo la modalidad de convivencia de hecho como un legítimo modelo de familia en el ordenamiento italiano. Esta disposición estatal obliga a los entes territoriales inferiores, que son quienes tienen competencia en esta materia, a adaptar su normativa para que exista una plena equiparación de derechos entre la familia tradicional y la de hecho ${ }^{54}$.

El aparado 46 de la Ley otorga derechos al conviviente de hecho que participe en la empresa familiar del otro conviviente, teniendo derecho a participar en los beneficios de la empresa del otro siempre y cuando aquel preste permanentemente su trabajo en ella. También tendrá derecho a participar en los bienes adquiridos con los beneficios de la empresa, así como a los incrementos que experimente el propio negocio ${ }^{55}$. No obstante, este precepto establece que no se aplicará este régimen en el caso de que exista una relación subordinada laboral entre los miembros de la pareja.

Por su parte, los apartados 47 y 48 hacen referencia a la posibilidad de que el conviviente de hecho sea tutor, curador o administrador de apoyo del otro conviviente en caso de que su capacidad sea modificada judicialmente.

El apartado 49 tiene como finalidad equiparar a los cónyuges y a los convivientes de hecho formalizados conforme a la Ley que se viene comentando, a efectos de considerarlos beneficiarios de la indemnización por la muerte del otro miembro, cuando la misma derive de un acto ilícito cometido por un tercero. En una primera etapa legislativa, únicamente eran beneficiarios de esta indemnización los cónyuges viudos, quedando excluidos los convivientes de hecho supérstites hasta la publicación definitiva de la Ley Cirinnà. No obstante, a partir de la década de los setenta, se fueron reconociendo ciertos derechos, por vía jurisprudencial, a los convivien-

54 RICCIO, A., "Art. 1c. 42-45”, en Le unioni civili e le convivenze. Commento alla legge n. 76/2016 e ai d.lgs. n. 5/2017; d.lgs. n. 6/2017; d.lgs. n. 7/2017, MASSIMO BIANCA, C. (cura), G. Giappichelli Editore, 2017, págs. 1311-1313.

55 MARTINO, M., "Art. 1 c. 46", en Le unioni civili e le convivenze. Commento alla legge n. 76/2016 e ai d.lgs. n. 5/2017; d.lgs. n. 6/2017; d.lgs. n. 7/2017, MASSIMO BIANCA, C. (cura), G. Giappichelli Editore, 2017, págs. 1313-1316. 
tes de hecho ${ }^{56}$. Además, también comenzaron a suprimirse algunas discriminaciones existentes en materia de filiación, pues desde la Ley 2012/219, de 10 de diciembre ${ }^{57}$, ya no se puede discriminar a los hijos en función de si han nacido en el seno de una familia matrimonial o extramatrimonial ${ }^{58}$. Como sucede con el reconocimiento de otros derechos en esta normativa, se exige que la pareja de hecho esté conformada de acuerdo con la ya analizada definición de convivencia de hecho del apartado 36. Ello supone que los miembros de la pareja, según interpretó la doctrina y la jurisprudencia en un primer momento, han de vivir juntos en el momento del fallecimiento. Este requisito de la convivencia en el momento del deceso ha traído importantes consecuencias a la hora de interpretar qué se entiende por convivencia de hecho, tal y como analizaremos más adelante ya que los criterios para entender que estamos en presencia de una familia de hecho se han flexibilizado, hasta el punto de reconocer la existencia de una familia de hecho, incluso si no hay convivencia ${ }^{59}$.

\section{B.2. Contrato de convivencia}

Tras el análisis del concepto de convivencia de hecho y de la regulación de los derechos que hemos visto que equiparan a este tipo de uniones con las matrimoniales, la Ley Cirinná se encarga de regular en los apartados 50 a 64 el contrato de convivencia. De este modo, además de la regulación de las uniones entre personas del mismo sexo a través de la institución de las uniones civiles o de la convivencia de hecho, esta norma destaca por la ordenación del contrato de convivencia, como un medio para regular las relaciones patrimoniales entre los convivientes de hecho. Así, regula su constitu-

56 IPPOLITI MARTINI, C., “Art. 1 c. 49”, en Le unioni civili e le convivenze. Commento alla legge n. 76/2016 e ai d.lgs. n. 5/2017; d.lgs. n. 6/2017; d.lgs. n. 7/2017, MASSIMO BIANCA, C. (cura), G. Giappichelli Editore, 2017, págs. 1324-1327.

57 LEGGE 10 dicembre 2012, n. 219. Disposizioni in materia di riconoscimento dei figli naturali. (12G0242) (GU Serie Generale n.293 del 17-12-2012).

${ }_{58}$ RUSSO, R., "Il punto di vista del giudice: famiglia di fatto e filiazione naturale", en La famiglia di fatto, CECCHELLA, C., (a cura), Edizioni PLUS - Università di Pisa, Italia, 2009, págs. 79-96.

59 En un sentido similar ya se pronunció el Tribunal de Milán en la ordenanza de 31 de mayo de 2016 donde se establecía que el párrafo 37 de la Ley de Cirinnà dispone que la declaración de convivencia tiene el propósito de determinar la «coexistencia estable», no reconocer esta última. Ello supone que la convivencia no es un requisito constitutivo de la familia de hecho, sino simplemente un requisito de prueba. (Tribunale di Milano, sezione IX, civile, ordinanza 31 maggio 2016. Buffone Estensore) 
ción, su contenido y las causas y consecuencias que se derivan de la ruptura de la relación de hecho y, por consiguiente, de las causas de nulidad y resolución del contrato de convivencia.

El apartado 50 es el encargado de legitimar a los convivientes de hecho a suscribir lo que la Ley denomina "contrato de convivencia", entendido como un instrumento que las partes han de suscribir y a través del cual pueden regular sus relaciones patrimoniales relacionadas con su vida en común ${ }^{60}$ constante la relación de pareja. En cuanto a la forma, $a b$ solemnitatem, la Ley establece que el contrato de convivencia ha de plasmarse por escrito, ya sea en escritura pública, o ya sea en escritura privada con firma autenticada de un notario o abogado que verifique el cumplimiento de las normas imperativas y que el contenido del contrato no sea contrario al orden público ${ }^{61}$. Por lo tanto, para dotar de eficacia a un contrato de convivencia tenemos dos posibles vías: o bien hacerlo directamente a través de documento público; o bien hacerlo en un documento privado que deberá, preceptivamente, ser autenticado por un notario o abogado que determine la legalidad de este. Además, esta misma forma $a b$ solemnitatem se requiere cuando, ya sean ambas partes de común acuerdo o una de ellas unilateralmente, decidan poner fin al contrato de convivencia y, por lo tanto, a la relación de hecho y; también cuando los convivientes quieran modificar o enmendar el contrato constante la relación de hecho ${ }^{62}$, lo que podrán llevar a cabo en cualquier momento que deseen.

A diferencia de lo que ocurre en el ordenamiento jurídico español donde los acuerdos entre las partes únicamente les vinculan a ellos, estos acuerdos que regulan las consecuencias patrimoniales de la pareja constante la convivencia en Italia tienen eficacia erga omnes desde el momento en que el apartado 52 de la Ley Cirinnà establece que el profesional que recibió la escritura en forma pública (o que autenticó la suscripción del acuerdo privado), tiene un plazo de 10 días para trasladar una copia al municipio de residencia común de los cohabitantes para su inscripción en el registro de conformidad con los artículos 5 (convivencia en el registro) y 7 (entradas de

60 OBERTO, G., “Art. 1 c. 50”, en Le unioni civili e le convivenze. Commento alla legge n. 76/2016 e ai d.lgs. n. 5/2017; d.lgs. n. 6/2017; d.lgs. n. 7/2017, MASSIMO BIANCA, C. (cura), G. Giappichelli Editore, 2017, págs. 1337-1338.

61 COSCIA, M., "La convivenza di fatto: riconoscimento e diritti", en Salvis Juribus, 2017. Disponible en: http://www.salvisjuribus.it/la-convivenza-di-fatto-riconoscimento-e-diritti/ (última consulta el 23/08/2020).

62 OBERTO, G. y PISCHETOLA, A., "Art. 1 c. 51", en Le unioni civili e le convivenze. Commento alla legge n. 76/2016 e ai d.lgs. n. 5/2017; d.lgs. n. 6/2017; d.lgs. $n$. 7/2017, MASSIMO BIANCA, C. (cura), G. Giappichelli Editore, 2017, págs. 1357-1360. 
registro) del reglamento a que se refiere el Decreto número 223 del Presidente de la República de 30 de mayo de 1989. Por tanto, desde el momento en que el contrato de convivencia está dotado de publicidad, ya podrá ser oponible frente a terceros.

Los apartados 53 a 56 se encargan de regular el contenido del contrato de convivencia. Este contenido podemos clasificarlo en contenido preceptivo, contenido dispositivo y contenido prohibido. En cuanto a aquello que debe de incluir el contrato de convivencia preceptivamente, el apartado 53 dispone que tienen que aparecer reflejadas las direcciones personales de los miembros de la pareja a efectos de notificaciones de todo aquello relativo al contrato de convivencia. La indicación de la dirección a efectos de notificaciones cobra una especial importancia, sobre todo, en el momento de la resolución unilateral del contrato de convivencia por una de las partes, ya que el apartado 61 establece que, en el caso de una resolución unilateral del contrato, el profesional deberá notificárselo a la otra parte en la dirección plasmada en el contrato de convivencia; dirección a la que se refiere el apartado $53^{63}$. Inmediatamente después del contenido preceptivo, el apartado 53 se encarga del contenido dispositivo o potestativo, donde se incluye el lugar de residencia común; el modo de contribución de cada cohabitante para sufragar los gastos comunes de su vida en común que podrán estipularse de acuerdo a sus capacidades económicas y también en función del trabajo de uno o ambos en el hogar; y, por último, también podrán incluir el régimen económico-patrimonial de comunidad de bienes (Della comunione legale) que aparece regulado en los artículos 177 y siguientes del CC italiano y está previsto para el matrimonio ${ }^{64}$. En relación con el régimen patrimonial escogido por las partes, el apartado 60

63 OBERTO, G., "Art. 1 c. 53", en Le unioni civili e le convivenze. Commento alla legge n. 76/2016 e ai d.lgs. n. 5/2017; d.lgs. n. 6/2017; d.lgs. n. 7/2017, MASSIMO BIANCA, C. (cura), G. Giappichelli Editore, 2017, págs. 1383-1384.

64 Si aplicamos analógicamente el artículo 177 del Código Civil Italiano de la comunidad legal o comunidad de bienes previsto para el matrimonio, tal y como establece el apartado 53 de la Ley Cirinnà, se entiende que son bienes de la comunidad legal constituida por los convivientes de hecho los siguientes: las compras realizadas por los convivientes conjuntamente o por separado constante la relación de hecho, excluyendo las relacionadas con los bienes personales (se consideran bienes personales los dispuestos en el artículo 179 del Código Civil italiano); los frutos civiles de las propiedades de cada uno de los convivientes recibidos y no consumidos en el momento de la disolución de la comunidad de bienes; los frutos del trabajo individual de cada conviviente si no han sido consumidos en el momento de la disolución; y, respecto de las empresas, pertenecen a la comunidad legal las administradas por ambos convivientes y las creadas después de la constitución de la convivencia de hecho. Ahora bien, en el caso de que las empresas sean de uno solo de los convivientes con anterioridad a la constitución de la unión de hecho, pero hayan

() UNED. Revista de Derecho UNED, núm. 27, 2021 
de la Ley establece que la resolución del contrato de convivencia (ya sea por acuerdo de las partes, de manera unilateral, por matrimonio posterior o unión civil o por muerte de uno de los convivientes) determina la disolución de la comunidad de bienes, aplicando, en la medida en que sea compatible, las disposiciones dictadas con respecto a la disolución de la comunidad de bienes prevista para el matrimonio recogida en el Código Civil. De este modo, podemos afirmar que, en el Derecho italiano, el régimen patrimonial de las parejas de hecho nace y muere con el nacimiento y la resolución del contrato de convivencia respectivamente.

Por último, el apartado 56 también hace mención del contenido que no puede plasmarse en el contrato de convivencia, cuando dispone que no podrá estar sometido a término o condición y, en caso de incluirse, se tendrá por no puesto. Así, el contrato de convivencia es para el ordenamiento italiano, al igual que el matrimonio, el reconocimiento del hijo natural, la adopción, la aceptación y la renuncia a la herencia, un llamado actus legitimus, o un acto cuya importancia social requiere que no haya incertidumbre sobre la existencia y la duración de los efectos legales.

El contrato de convivencia, como todo contrato, tiene unas causas específicas de nulidad, que podrán ser alegadas por cualquier interesado cuando en el momento de la celebración existiese un vínculo matrimonial, o una unión civil u otro contrato de convivencia en el que formasen parte alguno de los miembros de la pareja; también será nulo de pleno derecho cuando alguna de las partes fuese menor de edad o si tuviese modificada judicialmente la capacidad de obrar; además, será nulo si alguna de las partes ha sido condenada por el delito al que hace mención el artículo 88 del Código Civil ${ }^{65}$; en el caso de no ajustarse a los requisitos personales ya indicados del apartado 36 para entender que nos encontramos ante una convivencia de hecho también sería nulo radicalmente; $y$, por último, si atendemos a una interpretación sistemática del apartado 51 y 57 , se puede deducir que también será nulo el contrato de convivencia si no se hace bajo la forma $a b$ solemnitatem comentada, puesto que, en este caso, nos encontramos ante la ausencia de un elemento esencial del contrato, la forma.

Mención especial merece el apartado 58, que introduce una nueva patología contractual dentro de la llamada ineficacia tempo-

sido administradas por ambos, solo pertenecerán a la comunidad de bienes las ganancias y los beneficios, pero no la propia empresa como tal.

65 Vid. apartado 57, del artículo 1 de la Ley Cirinnà, de 20 de mayo de 2016. 
ral, pues nos habla de la suspensión de los efectos del contrato en determinadas situaciones ${ }^{66}$. Así, los efectos del contrato de convivencia permanecerán en suspenso mientras esté pendiente de resolución un proceso de interdicción judicial hasta que se decida si una persona posee las capacidades mentales suficientes para ejercer derechos y adquirir obligaciones; y también mientras haya un proceso abierto en relación al delito del artículo $88 \mathrm{CC}$ italiano hasta que haya una sentencia absolutoria, pues en caso de ser condenatoria, no se podría celebrar el contrato de convivencia al resultar nulo. Ello quiere decir que el contrato de convivencia permanecerá en suspenso en ambos procedimientos en tanto no haya una resolución que los ponga fin.

En lo que se refiere a las formas de terminación o resolución del contrato de convivencia, la Ley Cirinnà se encarga de regularlo en sus apartados 59 a 63 . El apartado 59 establece cuales son las cuatro formas posibles de resolución o terminación del contrato, a saber: por mutuo acuerdo entre las partes; de manera unilateral por uno solo de los miembros de la pareja; la celebración del matrimonio o la constitución de una unión civil entre los convivientes o entre uno de los convivientes con otra persona; y, la muerte de uno de los contratistas. En este punto, encontramos identidad de causas de terminación de la relación de hecho entre el ordenamiento jurídico italiano y el español ${ }^{67}$. Por tanto, la duración «natural» del contrato de convivencia coincide con la duración de la relación de convivencia. Por lo tanto, es lógico subordinar los efectos del contrato a la permanencia de la relación de convivencia. Esto no significa que haya algunos acuerdos diseñados para producir sus efectos desde la terminación de la relación de convivencia ${ }^{68}$, por ejemplo, los acuerdos que establecen las modalidades para definir las relaciones patrimoniales recíprocas constante la convivencia que pueden también contener estipulaciones relativas a la disolución del régimen patrimonial siempre y cuando esas disposiciones no sean

66 OBERTO, G., "Art. 1 c. 57-58", en Le unioni civili e le convivenze. Commento alla legge n. 76/2016 e ai d.lgs. n. 5/2017; d.lgs. n. 6/2017; d.lgs. n. 7/2017, MASSIMO BIANCA, C. (cura), G. Giappichelli Editore, 2017, págs. 1405-1410.

67 Artículo 4.1 de la Ley navarra, 6 de la Ley madrileña, 8 de la Ley balear, 4 de la Ley asturiana, 12 de la Ley andaluza, 9 de la Ley canaria, 5.1 Ley extremeña, 18 de la Ley vasca, 12 de la Ley cántabra, artículo 23 del Decreto 248/2007 de 20 de diciembre por el que se regula el Registro de Parejas de Hecho de Galicia, 7 del reglamento melillense, 234-3 de la Ley catalana, artículo 7 del ya derogado reglamento autonómico murcí, 309 de la Ley aragonesa, 5.1 de la Ley valenciana y artículo 9 de la Ley murcí.

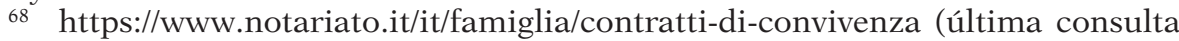
el 30/08/2020).

(C) UNED. Revista de Derecho UNED, núm. 27, 2021 
contrarias a derecho ni abusivas para las partes. De este modo, si este tipo de disposiciones están previstas en el contrato, ese contrato seguirá aplicándose después de la relación para regular, precisamente, los efectos de la disolución del régimen económico-patrimonial.

El apartado 60 se encarga de fijar la forma que debe tener la resolución o terminación del contrato que, tal y como mencionamos antes, es la misma que se exige para la suscripción del contrato de convivencia, esto es, o bien en documento público, o bien en documento privado autenticado por un profesional público o un abogado con los requisitos que menta el apartado 51. Además, este apartado establece que la terminación del contrato de convivencia supone también la disolución de la comunidad de bienes, en el supuesto de que sea el régimen patrimonial por el que optaron los convivientes mediante el contrato ${ }^{69}$.

Respecto del régimen económico patrimonial, podemos subrayar las diferencias en relación con el régimen patrimonial entre la unión civil y el matrimonio, por un lado, y las parejas que cohabitan de hecho por el otro: en el matrimonio y la unión civil, el régimen de comunión legal se establece automáticamente; esto es, si la pareja unida en matrimonio o en una unión civil tiene la intención de evitar el régimen de comunidad de bienes, deben estipular un acuerdo especial de separación, comunión convencional y fondo patrimonial; en el caso de las parejas de hecho, sin embargo, no se establece un régimen patrimonial subsidiario ${ }^{70}$, sino que los cohabitantes pueden decidir libremente el régimen patrimonial de la relación, estableciendo los métodos de contribución a las necesidades de la vida en común.

La Ley Cirinná dedica un apartado, el 61, a la resolución unilateral del contrato de convivencia. Este apartado establece que, en el caso de una resolución unilateral del contrato de convivencia, el profesional que recibe o autentica la escritura, además de las obligaciones mencionadas en el párrafo 52 (notificación del hecho al registro del municipio de residencia común de los convivientes), debe remitir al otro conviviente una copia de esta en la dirección prevista en el contrato. En el caso de que el hogar familiar sea propiedad exclusiva del que solicita la rescisión unilateralmente, en la declaración de resolución del contrato, so pena de nulidad, debe de contener el plazo, no inferior a noventa días, para que el otro conviviente abandone la

69 COSCIA, M., "La convivenza di fatto: riconoscimento... op. cit. Disponible en: http://www.salvisjuribus.it/la-convivenza-di-fatto-riconoscimento-e-diritti/ (última consulta el 30/08/2020).

70 https://www.notaiocarlocarbone.it/blog/archives/388 (última consulta el 03/08/2020). 
vivienda. Con esta última disposición el legislador italiano está protegiendo al conviviente que no manifiesta su deseo de terminar con el contrato de convivencia, otorgándole un periodo en el que podrá ocupar la vivienda de residencia habitual pese a no ser de su titularidad por un periodo determinado de tiempo ${ }^{71}$. Entendemos que este plazo se le otorga al conviviente no propietario para protegerlo de una posible situación de desamparo para aquellos supuestos en los que, por ejemplo, la ruptura de la relación pueda ser algo inesperado y, de este modo, tendrá un lapso temporal, no inferior a tres meses, para poder buscar una nueva vivienda. Este tipo de disposiciones son un claro ejemplo de la necesidad de que exista una Ley a nivel estatal en el ordenamiento jurídico español, pues como ya apuntamos, el uso y atribución de la vivienda habitual en España (art. 96 CC) no hace referencia a las uniones de hecho, las cuales se encuentran en una situación de inseguridad jurídica y deberán de atenerse a los que determine el juez en cada caso concreto en el supuesto de que no lleguen a un acuerdo.

Otro apartado, el 62, dedica la norma a la resolución del contrato en el caso de que, o bien las partes contraigan matrimonio o constituyan una unión civil entre sí, o bien que uno de los miembros de la pareja contraiga matrimonio o unión civil con otra persona. En este punto, la Ley establece que la parte que haya contraído matrimonio o unión civil debe remitir al otro contratista, así como al profesional que recibió o autenticó el contrato de convivencia, el certificado de matrimonio o unión civil. No obstante, la norma no establece cuáles son las consecuencias derivadas del incumplimiento de esta obligación de notificación. Nosotros entendemos que, en el supuesto de ausencia de notificación, la sanción no será otra que la rescisión del contrato con efectos retroactivos a la fecha de celebración del matrimonio o de la unión civil. Entendemos que no se estaría incurriendo en un delito de bigamia del artículo 556 del Código Penal italiano porque el mismo está reservado para la existencia de dos matrimonios con efectos civiles simultáneos, mientras que en este caso nos encontramos ante un matrimonio y una unión de hecho; además, tampoco podríamos hablar del delito de concubinato recogido en el artículo 560 del Código Penal italiano, pues dicho artículo fue declarado inconstitucional ${ }^{72}$.

71 https://www.notariato.it/it/famiglia/contratti-di-convivenza (última consulta el 03/08/2020).

72 Sentenza n. 147/1969 della Corte Costituzionale (Gazzetta ufficiale 10 dicembre 1969, n. 311).

(C) UNED. Revista de Derecho UNED, núm. 27, 2021 
El apartado 63 es el encargado de establecer las consecuencias de que el contrato de convivencia finalice por causa de muerte. Dispone que el supérstite o sus herederos estarán obligados a notificar al profesional que recibió o autenticó el contrato de convivencia, el certificado de defunción para que pueda anotar al margen del contrato la terminación de este y notificar dicho suceso al registro del municipio de residencia donde estaba inscrito el contrato, dando lugar con ello al fin del mismo ${ }^{73}$.

\section{B.3. Otros derechos de los convivientes de hecho}

Paralelamente a la mencionada lista de derechos reconocidos a la figura del conviviente de hecho recogidos en los apartados 38 a 49 de la Ley Cirinnà, el legislador regula una obligación particular impuesta a la pareja de facto, a saber, la obligación de proporcionar mantenimiento o sustento, o lo que es lo mismo, una figura paralela a la pensión compensatoria que recoge nuestro artículo 97 del Código Civil español, pero en este supuesto, prevista para el conviviente de hecho más perjudicado por la ruptura de la relación y no exclusivamente para los cónyuges. De hecho, el párrafo 65 establece que, en caso de cohabitación de facto, el juez puede establecer el derecho del cohabitante a recibir pensión alimenticia del otro cohabitante si se encuentra en un estado de necesidad y no puede mantenerse por sí mismo. Se entiende, que dicha pensión alimenticia, no corresponde siempre y en todo caso, sino únicamente cuando el conviviente que la solicita no tiene los medios necesarios para cubrir sus necesidades básicas por causas que no le sean imputables al mismo. Cuando dicha prestación proceda, la pensión alimenticia se asignará por un período proporcional a la duración de la convivencia y en la medida determinada de conformidad con el artículo 438 del Código Civil italiano ${ }^{74}$. En cuanto al orden de preferencia en caso de concurrir varios beneficiarios de dicha prestación, a los efectos de determinar el orden de los obligados de conformidad con el artículo 433 del código civil, la obligación de alimentos del conviviente de hecho se cumple con prioridad sobre los hermanos y hermanas,

73 OBERTO, G., “Art. 1 c. 59-63", en Le unioni civili e le convivenze. Commento alla legge n. 76/2016 e ai d.lgs. n. 5/2017; d.lgs. n. 6/2017; d.lgs. n. 7/2017, MASSIMO BIANCA, C. (cura), G. Giappichelli Editore, 2017, págs. 1416-1417.

${ }^{74}$ ALESSIO, A., "Contratto di convivenza: note prima lettura e modelo negoziale", en Studio Legale Associato, ALESSIO - SILVESTRI \& PARTNERS, 2016. Disponible en: http://www.asepartners.it/contratto-di-convivenza/ (última consulta el 20/08/2020). 
poniéndose, de este modo, en el mismo orden de prelación que si fuera un cónyuge.

En cuanto a la adopción, al igual que sucede con las uniones civiles entre personas del mismo sexo y con las personas solteras, está vetada para las uniones de hecho, puesto que la adopción en el ordenamiento jurídico italiano está subordinada a la existencia de un vínculo matrimonial. No obstante, existen algunos casos en los que los tribunales han permitido la adopción a las uniones de hecho, tras un análisis individual del caso concreto $^{75}$ pero, aun así, no podemos hablar de una adopción en los mismos términos que la adopción efectuada por un matrimonio. Por lo tanto, por regla general, los convivientes de hecho, ya sean heterosexuales u homosexuales, no pueden adoptar.

Ahora bien ¿tienen alguna otra opción para poder criar hijos o para poder formar una familia con hijos? La respuesta es afirmativa, pueden acudir a la institución del "affidamento" o acogimiento, ya que en caso de que un menor se encuentre en un ambiente familiar inadecuado, puede ser dado "temporalmente" en acogimiento a una familia de hecho ${ }^{76}$. De ello, deducimos que existe una gran desigualdad de trato entre los matrimonios y el resto de los modelos familiares en cuanto a la adopción se refiere. No compartimos el parecer del legislador italiano, pues a nuestro entender, un menor desamparado debiera de poder ser adoptado por cualquier tipo de familia que le proporcione las necesidades tanto económicas como afectivas necesarias para su correcto desarrollo, teniendo en cuenta las necesidades del menor y el interés superior del mismo, como sucede en el ordenamiento jurídico español, y no la orientación sexual de sus posibles progenitores adoptantes.

Hasta el momento ya hemos analizado lo que la Ley Cirinnà dispone para las uniones de hecho: su concepto; el contrato de convivencia y su contenido; así como los derechos de los convivientes en diferentes esferas jurídicas. Ahora bien, como adelantábamos, el concepto de convivencia de hecho experimentó una importante interpretación a raíz de una ordenanza de la Corte de Casación de 4 de mayo de 2018, sobre la que nos vamos a detener a continuación.

75 https://www.nostrofiglio.it/famiglia/adozione/convivenza-adozione\#affido (última consulta el 03/08/2020).

76 https://www.dirittierisposte.it/Schede/Famiglia/Convivenza/-e-unioni-di-fatto/ famiglia_di_fatto_id1109852_art.aspx (última consulta el/ 04/08/2020). 


\section{COMENTARIO DE LA ORDINAZA DE LA CORTE DI CASSAZIONE NÚM. 9178, DE 13 DE MAYO DE 2018.}

Como hemos adelantado, hasta el momento de la Ordenanza de Casación que vamos a analizar, además de los requisitos personales que ya hemos tenido ocasión de apuntar y que se encuentran recogidos en el apartado 36 de la Ley Cirinnà, se exigía el requisito objetivo de una convivencia efectiva. Veremos cómo esto ha cambiado hasta el punto de que actualmente no es necesario que esa convivencia sea efectiva, sino que basta con que el Juez examine todos los hechos conocidos surgidos durante el curso de la investigación, evaluándolos en su conjunto y uno a través del otro, lo que quiere decir que no será estrictamente necesario la concurrencia de una convivencia efectiva si se desprende de los demás elementos que los convivientes tienen una vida en común afectiva y con vocación de permanencia.

La resolución de la que venimos hablando es la Ordinanza della Corte di Cassazione núm. 9178, de 13 de mayo de 2018, Civile Ordine, Sezione 3, Anno 2018. La sentencia controvertida tiene su origen en el hecho de que la conviviente supérstite interpuso recurso de casación contra la sentencia núm. 4694/2013 de la Corte de Apelación de Milán que confirmó el rechazo del derecho a obtener la indemnización por causa de muerte del otro, quien perdió la vida al caer por el hueco del ascensor del edificio propiedad de Immobiliare Alfa (demandada), mientras se realizaban las renovaciones y obras oportunas. El motivo del rechazo de la indemnización por lesión fue porque el Tribunal de Apelación alegó que no existía prueba de la relación de convivencia, ya que las pruebas orales habían dado un resultado contradictorio, y de las conclusiones preliminares se desprende que el conviviente fallecido residía en un municipio distinto al de la conviviente supérstite en el momento del fallecimiento. Además, la Corte de Apelación de Milán había desestimado el recurso, al considerar que la prueba de la existencia de una convivencia estable entre el fallecido y la conviviente supérstite no emergía suficientemente del contexto probatorio, a pesar de que existían elementos idóneos para creer que existe una relación afectiva y de pareja, pero no un vínculo caracterizado por esa estabilidad y continuidad que legitima al conviviente para actuar por daños por pérdida de la relación afectiva y posiblemente por daño pecuniario derivado de la muerte del conviviente.

En relación con los motivos de apelación y en lo que aquí nos interesa, la demandante supérstite denuncia la violación y falsa errónea aplicación del art. 2 de la Constitución italiana en referen- 
cia a la calificación por parte del tribunal del concepto de familia de hecho, así como a la violación del art. 2059 del Código Civil italiano, con referencia al reconocimiento de las condiciones para la indemnización en caso de daño del familiar de hecho. De este modo, la recurrente alega que el Tribunal de Apelación no respetó el concepto de familia de hecho existente en el derecho vigente, en el que el elemento objetivo de la convivencia estable está asociado al elemento subjetivo de la afectividad. Señala que, en la evolución jurisprudencial, debido a los cambios en la vida social, se ha reconocido que, si bien es necesario a efectos de constatar la existencia de una convivencia de hecho la exteriorización de la estabilidad del vínculo afectivo compartiendo derechos y obligaciones, esta relación de hecho puede no ser necesariamente reconocida solo en presencia de convivencia. En particular el Tribunal de Casación recuerda que ha habido otras sentencias ${ }^{77}$ que se han pronunciado sobre esta cuestión y que determinaron que la convivencia de hecho como modelo familiar no tiene por qué coincidir necesariamente con la convivencia y define la convivencia de hecho como «el vínculo estable entre dos personas caracterizado por una comunidad de vida afectiva, duradera y significativa». Hay que señalar que la diferencia entre esas resoluciones y la que venimos analizando es que esta última es posterior a la promulgación de la Ley Cirinnà y que presenta una mayor claridad en cuanto aL concepto de convivencia de hecho ${ }^{78}$.

Según lo expuesto, el Tribunal de Casación sostiene que la Corte de Apelación, al valorar las instancias preliminares, incurrió en dos errores: en un error en la apreciación del hecho, devaluando la importancia de índices muy significativos de la existencia de una relación estable; y en un error de derecho, donde se limitó a considerar a la convivencia de hecho, como un modelo de familia fundamentado inextricablemente en la convivencia, sin considerar otros elementos importantes y concordantes como la existencia de una cuenta corriente común, la disponibilidad por parte de la demandante de las agendas de trabajo del fallecido, el hecho de que los carabineros recurrieran a ella inmediatamente después del siniestro indicándola en el acta como conviviente del fallecido... Así, entiende

77 Ordinanza della Corte di Cassazione, Civile Ordine, Sezione III, n. 7128, Año 2013.

78 GATTONI, D., "Convivenza anche senza coabitazioneIn nota a Cass. Civ., Sez. III, 13/04/2018, n. 9178”, en Ragionando_weblog. Il blog dello studio legale Lucenti e Gattoni stp, ISSN 2464-8833. Disponible en: https://www.jusdicere.it/Ragionando/avv-daniela-gattoni-la-convivenza-anche-senza-coabitazione/ (última consulta el 07/08/2020). 
el Tribunal de Casación que se ha acreditado la existencia de una relación estable y duradera que, incluso, ante una eventual falta de convivencia real y efectiva, puede considerarse a través de análisis de indicadores seguros la existencia de un vínculo estable, cuya pérdida es resarcible.

Finalmente, el Tribunal de Casación admite el recurso interpuesto por la recurrente supérstite y remite de nuevo el asunto al Tribunal de Milán para que resuelva atendiendo a las siguientes directrices y principios que recoge en el fallo de la resolución y que son: a) Hay convivencia de hecho relevante a efectos de la compensación del daño por lesión por fallecimiento si dos personas están unidas por un vínculo emocional estable y duradero, en virtud del cual asumen espontánea y voluntariamente compromisos mutuos de asistencia moral y material; y b) En orden a determinar la existencia de una convivencia de hecho, los requisitos de la importancia, de la precisión y de la concordancia de los elementos presuntivos requeridos por la ley, deben ser recabados en relación con el conjunto de los indicios (a título de ejemplo: un proyecto de vida en común, la existencia de una cuenta corriente conjunta, el sostenimiento conjunto de las cargas familiares y del hogar, la cohabitación) y no deben ser evaluados individualmente, sino en su conjunto y el uno por medio de los otros.

De ahí que la convivencia, que el Tribunal de Apelación entendió que era un requisito sine qua non, deba entenderse como un mero indicio o elemento presuntivo de la existencia de una convivencia de hecho, a considerar junto con los demás elementos probados y no como un elemento esencial de la misma, cuya posible falta, por sí misma, puede llevar legítimamente a la exclusión de la existencia de una convivencia ${ }^{79}$.

En conclusión, el Tribunal de Casación ha entendido que se puede hablar de la existencia de una convivencia de hecho, incluso en los supuestos en los que no exista una convivencia real, pues pueden existir estructuras familiares diferentes de la tradicional debidas a diferentes motivos. Así, en el caso objeto de estudio en la Sentencia que se viene comentando, los convivientes, efectivamente, no convivían en el mismo hogar habitualmente porque el fallecido tenía y debía habitar en otro municipio por motivos laborales para sustentar a la familia. Es por ello que el Tribunal de Casación entiende que, en la estructura cambiante de la sociedad, en

79 AMILCARE, M., "Convivenza di fatto, precisazioni dalla Cassazione", en Diritto.it. Fundatore Francesco Brugaletta, ISSN 1127-8579, Maglitori Editore, 2018. Disponible en: https://www.diritto.it/la-convivenza-precisazioni-dalla-cassazione/ (última consulta el 07/08/2020). 
la vida moderna, los ritmos, compromisos, hábitos... pueden llevar a la pareja a vivir a distancia, sin menoscabo, sin embargo, de la solidez del vínculo emocional, que es el único elemento que también cuenta a efectos legales.

Por tanto, tal y como se adelanta en páginas precedentes, esta sentencia ha supuesto un antes y un después en relación con los ha de entenderse por convivencia de hecho. De un lado, ya vimos como de una interpretación sistemática de los apartados 36 y 37 de la Ley Cirinnà, se desprendía que la convivencia era, junto con los requisitos personales, un requisito constitutivo de la convivencia de hecho. Sin embargo, vemos ahora cómo la jurisprudencia italiana ha establecido que, si bien es importante la existencia de la convivencia, no es un requisito esencial del concepto, siempre y cuando del resto de hechos (cuentas conjuntas, relación afectiva, sostenimiento equitativo de los gastos familiares...) se desprenda que existe una relación afectiva.

\section{CONCLUSIONES}

Lo primero que nos gustaría destacar es que la Ley núm. 76, de 20 de mayo del Ordenamiento Jurídico italiano está regulando dos instituciones familiares diferentes. Por un lado, la institución de las uniones civiles, prevista en exclusiva para las uniones entre personas del mismo sexo y que, hemos visto se asemeja en la mayor parte de su régimen legal al previsto para el matrimonio y que es una institución homónima al matrimonio igualitario español; y, por otro lado, la institución de la convivencia de hecho cuyo símil en el Ordenamiento Jurídico español es el de las parejas de hecho.

Como puede observarse tras el análisis de la Ley Cirinnà, el Estado italiano dispone de una rigurosa regulación de ambas instituciones, con un rigorismo similar al matrimonial desde el momento en el que regulan sus formas de constitución; así como los derechos personales y patrimoniales de las partes; y los modos y efectos de su disolución.

Entendemos que el punto álgido de esta reglamentación son las exhaustivas disposiciones relativas al contrato de convivencia, pese a que lo más destacable, a nuestro parecer, es que la regulación se ha hecho por parte del legislador estatal y, de esta forma, toda la norma es aplicable a todo el territorio nacional, no como hemos señalado que sucede en el ordenamiento jurídico español, donde la regulación, básicamente, ha sido pergeñada por los legisladores autonómi- 
cos con las patentes desigualdades que planteamos en su momento y, sobre todo, con las importantes dudas sobre la constitucionalidad de la mayor parte de dichas normas.

Todo ello nos hace plantearnos la necesidad de proponer una reforma que, al menos, suponga una intervención por parte del legislador estatal, consistente en la elaboración de un concepto único de pareja de hecho para todo el territorio nacional y que así, cuando las disposiciones hagan referencia a las parejas de hecho, se tenga la certeza de saber a qué concreta situación de hecho nos estamos refiriendo. La regulación italiana, en los términos que han sido apuntados, entendemos que sería capaz de cubrir las lagunas legales en materia de atribución y uso de la vivienda familiar, de los derechos sucesorios, así como resolver la situación de inseguridad jurídica que todo ello conlleva para las personas que optan por este modelo familiar para constituir una familia en España.

En suma, al igual que en su momento el legislador español tomó ejemplo el Código Napoleónico para elaborar su Código Civil, podría ahora tomar como ejemplo la Ley Cirinná para complementar las lagunas legales de la institución de las parejas de hecho en el Ordenamiento Jurídico español.

\section{BIBLIOGRAFÍA:}

Alessio, A., "Contratto di convivenza: note prima lettura e modelo negoziale", en Studio Legale Associato, Alessio - Silvestri \& PARTNERS, 2016.

Amilcare, M., "Convivenza di fatto, precisazioni dalla Cassazione", en Diritto.it. Fundatore Francesco Brugaletta, ISSN 1127-8579, Maglitori Editore, 2018.

ANgeli, F., Coppia e famiglia tra desiderio di mutamento e ricerca di stabilità, Unione italiana consultori prematrimoniali e matrimoniali, 1998.

Ayllón García, J.D., «Discriminación normativa de las parejas de hecho: TRHA y adopción», en Revista de Derecho de Familia, núm. 73, Aranzadi, 2016.

AYllón García, J.D., "Presente y futuro del derecho sucesorio de las parejas de hecho», en De Sales Capilla Roncero, F.; EsPejo Lerdo De Tejada, M.; y Aranguren URriza, F.J. (Dir.) Las legítimas y la libertad de testar: Perfiles críticos y comparados, Aranzadi, 2019. 
Blanca, M., "Il comma 20 quale crocevia per l'inserimento della nuova disciplina delle unioni civile nel sistema", en Le unioni civili e le convivenze. Commento a la legge n. 76/2016 e ai d.lgs. n. 5/2017; d.lgs. n. 6/2017; d.lgs. n. 7/2017, MASSIMO BIANCA, C. (cura), G. Giappichelli Editore, 2017.

Carbone, C., "Unioni civili tra persone dello stesso sesso e disciplina delle convivenze", en Appendice di aggiomamento al formulario notarile commentato, Wolkers Kluwer, Italia, 2016.

CipPitani, R. y Colcelli, V., "La función innovadora del interés del menor en la jurisprudencia italiana", en El interés superior del niño en la jurisprudencia internacional, comparada y española, SANZ CABALLERo, S. (Dir.), Aranzadi, Thomson Reuters, 2017.

Coscia, M., "La convivenza di fatto: riconoscimento e diritti", en Salvis Juribus, 2017.

Dell'anna Misurale, F., "Unioni civili tra diritto e pregiudizio. Prima lettura del nuovo testo di legge", en Giustiziacivile.com, núm. 6, 2016.

FERRANDO, G., "Le unioni civili: la situazione in Italia", en Giurisprudenza Italiana, 2016.

GatToni, D., "Convivenza anche senza coabitazioneIn nota a Cass. Civ., Sez. III, 13/04/2018, n. 9178”, en Ragionando_weblog. Il blog dello studio legale Lucenti e Gattoni stp, ISSN 2464-8833.

IpPoltti Martini, C., “Art. 1 c. 49”, en Le unioni civili e le convivenze. Commento alla legge n. 76/2016 e ai d.lgs. n. 5/2017; d.lgs. n. 6/2017; d.lgs. n. 7/2017, MASSIMO BIANCA, C. (cura), G. Giappichelli Editore, 2017.

Martín Casals, M., "Informe de Derecho comparado sobre la regulación de la pareja de hecho", en Anuario de Derecho Civil, Fascículo 4, 1995.

Martino, M., "Art. 1 c. 46", en Le unioni civili e le convivenze. Commento alla legge n. 76/2016 e ai d.lgs. n. 5/2017; d.lgs. n. 6/2017; d.lgs. n. 7/2017, MASsimo BiancA, C. (cura), G. Giappichelli Editore, 2017.

Massimo Bianca, C., "L'introduzione dell' unione civile" en Le unioni civili e le convivenze. Commento a la legge n. 76/2016 e ai d.lgs. $n$. 5/2017; d.lgs. n. 6/2017; d.lgs. n. 7/2017, MAssimo BianCA, C. (cura), G. Giappichelli Editore, 2017. 
Oberto, G. y Pischetola, A., “Art. 1 c. 51", en Le unioni civili e le convivenze. Commento alla legge n. 76/2016 e ai d.lgs. n. 5/2017; d.lgs. n. 6/2017; d.lgs. n. 7/2017, Massimo BiancA, C. (cura), G. Giappichelli Editore, 2017.

Oberto, G., "Art. 1 c. 50", en Le unioni civili e le convivenze. Commento alla legge n. 76/2016 e ai d.lgs. n. 5/2017; d.lgs. n. 6/2017; d.lgs. n. 7/2017, Massimo Bianca, C. (cura), G. Giappichelli Editore, 2017.

Oberto, G., “Art. 1 c. 53”, en Le unioni civili e le convivenze. Commento alla legge n. 76/2016 e ai d.lgs. n. 5/2017; d.lgs. n. 6/2017; d.lgs. n. 7/2017, Massimo Bianca, C. (cura), G. Giappichelli Editore, 2017.

Oberto, G., "Art. 1 c. 57-58”, en Le unioni civili e le convivenze. Commento alla legge n. 76/2016 e ai d.lgs. n. 5/2017; d.lgs. n. 6/2017; d.lgs. n. 7/2017, Massimo Bianca, C. (cura), G. Giappichelli Editore, 2017.

Oberto, G., "Art. 1 c. 59-63”, en Le unioni civili e le convivenze. Commento alla legge n. 76/2016 e ai d.lgs. n. 5/2017; d.lgs. n. 6/2017; d.lgs. n. 7/2017, Massimo Bianca, C. (cura), G. Giappichelli Editore, 2017.

PizzuTi, P., "Uniones civiles y relación laboral en el ordenamiento italiano", en Temas laborales núm. 149, 2019.

PRISCO, I., "Il pluralismo familiare in italia: unioni civili e convivenze", en Actualidad Jurídica Iberoamericana Núm. 11, agosto 2019.

Riccio, A., "Art. 1c. 42-45”, en Le unioni civili e le convivenze. Commento alla legge n. 76/2016 e ai d.lgs. n. 5/2017; d.lgs. n. 6/2017; d.lgs. n. 7/2017, Massimo Bianca, C. (cura), G. Giappichelli Editore, 2017.

Russo, R., "Il punto di vista del giudice: famiglia di fatto e filiazione naturale", en La famiglia di fatto, CECCHELla, C., (a cura), Edizioni PLUS - Università di Pisa, Italia, 2009.

Tonolo, S., “Art. 1 c. 64", en Le unioni civili e le convivenze. Commento alla legge n. 76/2016 e ai d.lgs. n. 5/2017; d.lgs. n. 6/2017; d.lgs. n. 7/2017, Massimo BIANCA, C. (cura), G. Giappichelli Editore, 2017.

VenUtI, M.c., "La regolamentazione delle unioni civili tra persona dello stesso sesso e delle convivenze in Italia", en Política del diritto, núm. 47, 2016. 